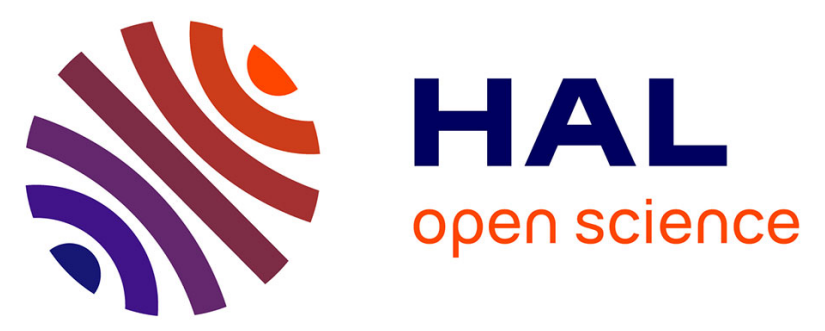

\title{
New insights into tetrahydrobiopterin pharmacodynamics from, a mouse model for compound heterozygote tetrahydrobiopterin-responsive phenylalanine hydroxylase deficiency
}

Florian B. Lagler, Søren W. Gersting, Clemens Zsifkovits, Alice Steinbacher, Anna Eichinger, Marta K. Danecka, Michael Staudigl, Ralph Fingerhut, Hartmut Glossmann, Ania C. Muntau

\section{- To cite this version:}

Florian B. Lagler, Søren W. Gersting, Clemens Zsifkovits, Alice Steinbacher, Anna Eichinger, et al.. New insights into tetrahydrobiopterin pharmacodynamics from, a mouse model for compound heterozygote tetrahydrobiopterin-responsive phenylalanine hydroxylase deficiency. Biochemical Pharmacology, 2010, 80 (10), pp.1563. 10.1016/j.bcp.2010.07.042 . hal-00626236

\section{HAL Id: hal-00626236 https://hal.science/hal-00626236}

Submitted on 24 Sep 2011

HAL is a multi-disciplinary open access archive for the deposit and dissemination of scientific research documents, whether they are published or not. The documents may come from teaching and research institutions in France or abroad, or from public or private research centers.
L'archive ouverte pluridisciplinaire HAL, est destinée au dépôt et à la diffusion de documents scientifiques de niveau recherche, publiés ou non, émanant des établissements d'enseignement et de recherche français ou étrangers, des laboratoires publics ou privés. 


\section{Accepted Manuscript}

Title: New insights into tetrahydrobiopterin pharmacodynamics from $\mathrm{Pah}^{\text {enul/2}}$, a mouse model for compound heterozygote tetrahydrobiopterin-responsive phenylalanine hydroxylase deficiency

Authors: Florian B. Lagler, Søren W. Gersting, Clemens

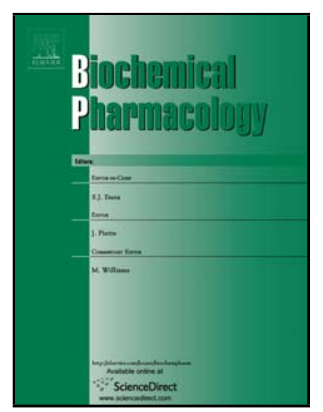
Zsifkovits, Alice Steinbacher, Anna Eichinger, Marta K. Danecka, Michael Staudigl, Ralph Fingerhut, Hartmut Glossmann, Ania C. Muntau

PII: S0006-2952(10)00580-0

DOI: doi:10.1016/j.bcp.2010.07.042

Reference: BCP 10675

To appear in: $\quad B C P$

Received date: $\quad$ 9-6-2010

Revised date: 24-7-2010

Accepted date: $\quad$ 28-7-2010

Please cite this article as: Lagler FB, Gersting SW, Zsifkovits C, Steinbacher A, Eichinger A, Danecka MK, Staudigl M, Fingerhut R, Glossmann H, Muntau AC, New insights into tetrahydrobiopterin pharmacodynamics from Pahenul/2, a mouse model for compound heterozygote tetrahydrobiopterin-responsive phenylalanine hydroxylase deficiency, Biochemical Pharmacology (2010), doi:10.1016/j.bcp.2010.07.042

This is a PDF file of an unedited manuscript that has been accepted for publication. As a service to our customers we are providing this early version of the manuscript. The manuscript will undergo copyediting, typesetting, and review of the resulting proof before it is published in its final form. Please note that during the production process errors may be discovered which could affect the content, and all legal disclaimers that apply to the journal pertain. 
New insights into tetrahydrobiopterin pharmacodynamics from $\mathrm{Pah}^{\text {enu1/2 }}$, a mouse model for compound heterozygote tetrahydrobiopterin-responsive phenylalanine hydroxylase deficiency

Florian B. Lagler ${ }^{\mathrm{a}, 1}$, Søren W. Gersting ${ }^{\mathrm{b}, 1}{ }$, Clemens Zsifkovits ${ }^{\mathrm{a}}$, Alice Steinbacher ${ }^{\mathrm{b}}$, Anna Eichinger ${ }^{\mathrm{b}}$, Marta K. Danecka ${ }^{\mathrm{b}}$, Michael Staudigl ${ }^{\mathrm{b}}$, Ralph Fingerhut ${ }^{\mathrm{c}, \mathrm{d}}$, Hartmut Glossmann ${ }^{a}$, Ania C. Muntau ${ }^{\text {b, * }}$

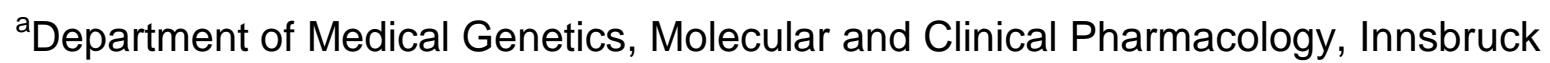
Medical University, 6020 Innsbruck, Austria

'Department of Molecular Pediatrics, Dr von Hauner Children's Hospital, LudwigMaximilians-University, 80337 Munich, Germany

'Laboratory Becker, Olgemöller, and colleagues, 81671 Munich, Germany

dNewborn Screening Laboratory, University Children's Hospital, 8032 Zurich,

Switzerland

${ }^{1}$ These authors contributed equally to this work.

* Corresponding author at: Children's Research Center, Dr von Hauner Children's Hospital, Ludwig-Maximilians-University, 80337 Munich, Germany.

Tel.: +49 895160 2746: fax +498951607952.

E-mail address: ania.muntau@med.Imu.de (Ania C. Muntau) 
Abbreviations:

PKU, phenylketonuria; $\mathrm{PAH}$, phenylalanine hydroxylase; $\mathrm{BH}_{4}, 6$ R-L-erythro-5,6,7,8tetrahydrobiopterin; MIM, Mendelian Inheritance in Man number; EC, Enzyme Commission number; MHP, mild hyperphenylalaninemia; enu, N-ethyl-N-nitrosourea; BTBR, black and tan brachyuric mouse strain; DTT, dithiothreitol; $\mathrm{K}_{\mathrm{e}}$, elimination constant; $\mathrm{c}_{0}$, initial concentration; $\mathrm{c}_{\max }$, peak concentration; $\mathrm{t}_{\max }$, time to peak concentration; AUC, area under the concentration vs. time curve at 0 to 180 minutes; $t_{1 / 2}$, elimination half-life; ${ }^{13} \mathrm{C}$-phenylalanine, L-[1-13]C-phenylalanine; DOB, delta over baseline; $\mathrm{DOB}_{\mathrm{BH} 4}$, delta over baseline after $\mathrm{BH}_{4}$ treatment; $\mathrm{DOB}_{\text {Placebo, delta over }}$ baseline after Placebo; Phe $_{0}$, initial phenylalanine concentration; Phe $_{180,}$ phenylalanine concentration at 180 minutes. 


\section{ABSTRACT}

Phenylketonuria (PKU), an autosomal recessive disease with phenylalanine hydroxylase (PAH) deficiency, was recently shown to be a protein misfolding disease with loss-of-function. It can be treated by oral application of the natural PAH cofactor tetrahydrobiopterin $\left(\mathrm{BH}_{4}\right)$ that acts as a pharmacological chaperone and rescues enzyme function in vivo. Here we identified $P a h^{e n u 1 / 2}$ bearing a mild and a severe mutation (V106A/F363S) as a new mouse model for compound heterozygous mild $\mathrm{PKU}$. Although $\mathrm{BH}_{4}$ treatment has become established in clinical routine, there is substantial lack of knowledge with regard to $\mathrm{BH}_{4}$ pharmacodynamics and the effect of the genotype on the response to treatment with the natural cofactor. To address these questions we applied an elaborate methodological setup analyzing (i) blood phenylalanine elimination, (ii) blood phenylalanine/tyrosine ratios, and (iii) kinetics of in vivo phenylalanine oxidation using ${ }^{13} \mathrm{C}$-phenylalanine breath tests. We compared pharmacodynamics in wild-type, $P a h^{\text {enu1/1/1 }}$, and $P a h^{\text {enu1/2 }}$ mice and observed crucial differences in terms of effect size as well as effect kinetics and dose response. Results from in vivo experiments were substantiated in vitro after overexpression of wild-type, V106A, and F263S in COS-7 cells. Pharmacokinetics did not differ between $P a h^{e n u 1 / 1}$ and $P a h^{e n u 1 / 2}$ indicating that the differences in pharmacodynamics were not induced by divergent pharmacokinetic behavior of $\mathrm{BH}_{4}$. In conclusion, our findings show a significant impact of the genotype on the response to $\mathrm{BH}_{4}$ in $\mathrm{PAH}$ deficient mice. This may lead to important consequences concerning the diagnostic and therapeutic management of patients with PAH deficiency underscoring the need for individualized procedures addressing pharmacodynamic aspects. 


\section{Introduction}

Phenylketonuria (PKU; [MIM 261600]) is an autosomal recessive inborn error of metabolism caused by deficiency of hepatic phenylalanine-4-hydroxylase (PAH; EC 1.14.16.1). PAH catalyzes the rate-limiting step in phenylalanine catabolism and is regulated by binding of its L-phenylalanine substrate and the cofactor $6 R$-L-erythro5,6,7,8-tetrahydrobiopterin $\left(\mathrm{BH}_{4}\right)$ and by phosphorylation [1-3]. Mutations in the $P A H$ gene lead to loss of function of the PAH protein, which is often induced by protein misfolding [4]. The clinical phenotypes of hyperphenylalaninemia due to PAH deficiency are classified from classic PKU (blood phenylalanine concentrations > 1,200 $\mu \mathrm{M})$ to mild PKU (600 to $1,200 \mu \mathrm{M})$ and mild hyperphenylalaninemia (MHP, 120 to $600 \mu \mathrm{M})$. Patients with classic and mild PKU need lifelong treatment to prevent mental retardation, whereas the necessity of MHP treatment is under debate $[5,6]$. In the last sixty years the only treatment available for patients with $\mathrm{PAH}$ deficiency was dietary phenylalanine restriction, a burdensome treatment associated with significant risks of malnutrition. A paradigm change occurred ten years ago when researchers observed that pharmacological doses of the natural PAH cofactor, $\mathrm{BH}_{4}$, can reduce blood phenylalanine concentrations in a significant number of patients that do not display one of the rare forms of $\mathrm{BH}_{4}$ deficiency [7-9]. This led to definition of a new clinical phenotype, $\mathrm{BH}_{4}$-responsive $\mathrm{PAH}$ deficiency. Efficacy and safety of sapropterin dihydrochloride, the synthetic form of $\mathrm{BH}_{4}$, was subsequently demonstrated in clinical trials [10-13] and the Food and Drug Administration (FDA) and the European Medicines Agency (EMEA) approved Kuvan ${ }^{\circledR}$ (Merck Serono) as an orphan drug to treat $\mathrm{BH}_{4}$-responsive $\mathrm{PAH}$ deficiency. However, at the time of market approval the molecular mode of action of the new drug was not well understood. By now, analyses of the pharmacological $\mathrm{BH}_{4}$ effect in vitro performed 
by different groups have provided evidence for structural stabilization of misfolded $\mathrm{PAH}$ indicating a pharmacological chaperone mode of action of $\mathrm{BH}_{4}[14-16]$. In addition, an animal model with the specific clinical and biochemical phenotype of $\mathrm{BH}_{4}$-responsive $\mathrm{PAH}$ deficiency was not available for drug approval. PAH deficiency in mice has previously been generated by germline mutagenesis $[17,18]$. The $\mathrm{V} 106 \mathrm{~A}$ mutation in $P a h^{\text {enu1/1 }}$ leads to a MHP phenotype [17], whereas $P a h^{\text {enu2/2, harboring }}$ the null mutation F263S, shows classical PKU (www.pahdb.mcgill.ca) [18-20]. We recently showed that mice homozygous for the V106A mutation display a molecular phenotype of protein misfolding with loss-of-function and that $P a h^{e n u 1 / 1}$ is an animal model for the clinical phenotype of $\mathrm{BH}_{4}$-responsive MHP [16]. However, patients that most benefit from treatment with $\mathrm{BH}_{4}$ are those with mild $\mathrm{PKU}[8,21,22]$. Moreover, the majority of patients ( $87 \%$ ) with $\mathrm{BH}_{4}$-responsive $\mathrm{PAH}$ deficiency are compound heterozygous carrying two different mutations on the maternal and the paternal allele [23] with about $26 \%$ of the alleles being putative null mutations. Recent studies showed a marked influence of the patient's genotype on the intensity and time frame of response to $\mathrm{BH}_{4}[24-26]$.

Previous clinical studies mostly analyzed the effect of $\mathrm{BH}_{4}$ on the patients' blood phenylalanine level, an endpoint with limited functional value. We showed that the effect of $\mathrm{BH}_{4}$ on blood phenylalanine concentrations in humans is accompanied by an increase in PAH function in vivo [8] and recently replicated this in the mouse model $\operatorname{Pah}^{\text {enu1/1 }}[16]$. However, comprehensive pharmacodynamic and pharmacokinetic studies in a specific mouse model displaying the clinical phenotype of $\mathrm{BH}_{4}-$ responsive $\mathrm{PAH}$ deficiency are still not available.

Thus, the aims of this study were (i) to investigate whether the compound heterozygous strain $\mathrm{Pah}^{\text {enu1/2 }}$ is a model for $\mathrm{BH}_{4}$-responsiveness in mild $\mathrm{PKU}$ and (ii) to characterize pharmacodynamics and pharmacokinetics of $\mathrm{BH}_{4}$ treatment in the 
mouse models $P a h^{\text {enu1/1 }}$ and $P a h^{\text {enu1/2 }}$. Our results show that $P a h^{\text {enu1/2 }}$ is a model for compound heterozygous mild $\mathrm{PKU}$ with $\mathrm{BH}_{4}$-responsiveness. Pharmacodynamics of $\mathrm{BH}_{4}$, in particular with respect to effect size and effect kinetics differed significantly in both strains, while pharmacokinetics was congruent.

\section{Materials and Methods}

\subsection{Animals}

BTBR, $P a h^{e n u 1 / 1}$ and $P a h^{e n u 2 / 2}$ mice were purchased from Jackson Laboratory (Bar Harbor, USA). The compound heterozygous hybrids $P a h^{\text {enu1/2 }}$ were crossbred in our animals' facility. The animals were housed under controlled temperature conditions and maintained on a cycle of 12 hours light/dark period. Between experiments water and food were available ad libitum. Basic blood phenylalanine concentrations and response to a single dose of $\mathrm{BH}_{4} 20 \mu \mathrm{g} / \mathrm{g}$ body weight (bw) without phenylalanine load were assessed after 1 hour fasting from food to minimize postprandial phenylalanine fluctuations. All blood samples were taken from the tail and collected on filter cards. All animal experiments were approved by the Austrian Ministry of Science. Tests were carried out in adult animals at 3 to 6 months of age.

2.2 Combined phenylalanine- $\mathrm{BH}_{4}$ loading tests and ${ }^{13} \mathrm{C}$-phenylalanine breath tests In order to minimize the influence of naturally occurring ${ }^{13} \mathrm{C}$ from food and to standardize phenylalanine supply, the experiments were performed after an overnight deprivation of food, whereas free access to water was allowed.

\subsubsection{Combined phenylalanine- $\mathrm{BH}_{4}$ loading test}

Unlabelled L-phenylalanine (Sigma Aldrich, St. Louis, USA) $15 \mu \mathrm{g} / \mathrm{g}$ bw and $\mathrm{BH}_{4}$ (Cayman Chemicals, Tallin, Estonia) $20 \mu \mathrm{g} / \mathrm{g}$ bw or placebo (sodium chloride $0.9 \%$, 
ascorbic acid $1 \%$ ) were simultaneously injected intraperitoneally (i.p.). The compounds were dissolved in a sodium chloride $0.9 \%$ (B. Braun, Melsungen, Germany), ascorbic acid (Merck, Darmstadt, Germany) $1 \%$ solution at concentrations of $3 \mu \mathrm{g} / \mathrm{ml}$ (L-phenylalanine) and $4 \mu \mathrm{g} / \mathrm{ml}\left(\mathrm{BH}_{4}\right)$ resulting in an injection volume of $5 \mu \mathrm{l} / \mathrm{g}$. Venous blood samples of approximately $40 \mu \mathrm{l}$ were collected on filter cards before and 20, 40, 60, 120, and 180 minutes after injection. Blood phenylalanine and tyrosine were quantified by electron spray ionization-tandem mass spectrometry. Blood phenylalanine elimination was analyzed by non-linear curve fitting of the concentrations at 20-180 minutes using a single exponential function: $Y=(Y 0-$ Plateau $) \times\left(e^{-K \times X}\right)+$ Plateau

\subsection{2 ${ }^{13} \mathrm{C}$-phenylalanine breath tests}

L-[1-13]C-phenylalanine $\left({ }^{13} \mathrm{C}\right.$-phenylalanine, Eurisotop, Saint-Aubin Cedex, France) was injected in a dose of $15 \mu \mathrm{g} / \mathrm{g}$ bw i.p. simultaneously with $\mathrm{BH}_{4}$ or placebo. Preparation and application of the compounds were performed as described above. Mice were placed in individual $100 \mathrm{ml}$ breath chambers with a continuous flow of $\mathrm{CO}_{2}$-free air. Breath samples were collected in 6.5 minute intervals over a 104 minute period. For each sample the airflow was discontinued for 90 seconds to allow $\mathrm{CO}_{2}$ levels to accumulate above $0.8 \%$. At the end of accumulation the sample was insufflated into an infrared spectrometer (IRIS Wagner Analysen Technik, Bremen, Germany) for online isotope analysis. The cumulative recovery of ${ }^{13} \mathrm{C}$ was calculated based on the ratio of ${ }^{13} \mathrm{CO}_{2}$ to ${ }^{12} \mathrm{CO}_{2}$ as previously described [27], assuming a total $\mathrm{CO}_{2}$ production rate of $94 \mathrm{ml}$ per min per $\mathrm{g} \mathrm{bw} \mathrm{x} \mathrm{m}^{2}$ body surface area [28]. For dose response studies, $\mathrm{BH}_{4}$ was given in doses of $5,10,20,30$, and $40 \mu \mathrm{g} / \mathrm{g} \mathrm{bw}$, respectively. To analyze the effect duration, $40 \mu \mathrm{g} / \mathrm{g}$ bw of $\mathrm{BH}_{4}$ were given $90,24,18$, 
$9,6,4.5$ or 3 hours before or simultaneously to ${ }^{13} \mathrm{C}$-phenylalanine. Subsequently, the cumulative recovery of ${ }^{13} \mathrm{CO}_{2}$ was determined at 104 minutes.

\section{$2.3 \mathrm{BH}_{4}$ pharmacokinetics}

In order to determine pharmacokinetics, $\mathrm{BH}_{4}$ at a dose of $20 \mu \mathrm{g} / \mathrm{g}$ bw was prepared and injected as described above. Venous blood samples (approximately $40 \mu \mathrm{l}$ ) were collected on filter cards before and 20,40,60, 120, and 180 minutes after injection. Total biopterin $\left(\mathrm{BH}_{4}\right.$, dihydrobiopterin, and biopterin) was quantified by High Pressure Liquid Chromatography (HPLC) as previously described [29, 30]. Biopterin clearance was determined by non-linear regression of a double exponential Bateman function as described by Koch et al. [31].

\subsection{Transient expression of PAH in COS-7}

COS-7 cells were maintained in basic RPMI 1640 medium (PAA Laboratories, Pasching, Austria) with stable glutamine supplemented with $10 \%$ fetal bovine serum (PAA) and $1 \%$ antibiotics (Antibiotic-Antimycotic; PAA). For transient expression of the murine wild-type and variant PAH pEF-DEST51 (Invitrogen, San Diego, USA) cDNA constructs coding for wild-type, V106A, and F263S PAH were used in single transfection (wild-type, $P a h^{\text {enu1/1 }}, P a h^{\text {enu2/2 }}$ ) or co-transfection $\left(P^{2} h^{\text {enu1/2}}\right)$. A total amount of $3 \mu \mathrm{g}$ DNA per 1 million cells was applied using the Amaxa electroporation system (Lonza, Basel, Switzerland). Cells were cultured for 24 and 72 hours under two different conditions: i) basic medium (as described above), ii) basic medium with $43 \mu \mathrm{M} \mathrm{BH}_{4}, 5 \mu \mathrm{g} / \mathrm{ml}$ ascorbic acid, and $1 \mathrm{mM}$ L-phenylalanine. Culture medium was changed every 24 hours. The cells were harvested and lysed by three freeze-thaw cycles in a lysis buffer containing $1 \%$ Triton X-100 and proteinase inhibitors, followed 
by 20 minutes centrifugation at $14,000 \mathrm{rpm}, 4^{\circ} \mathrm{C}$. Recovered supernatants were subsequently used for activity assays [4].

\subsection{PAH activity assay}

PAH enzyme activity was determined as previously described [4, 32, 33] with modifications. $20 \mu \mathrm{l}$ of total lysates obtained from cell culture were preincubated with $1 \mathrm{mM}$ L-phenylalanine and catalase $1 \mathrm{mg} / \mathrm{ml}$ (Sigma Aldrich, St. Louis, USA) for 5 minutes $\left(25^{\circ} \mathrm{C}\right)$ in $15 \mathrm{mM} \mathrm{Na}$ HEPES pH 7.3, followed by 1 minute incubation with 10 $\mu \mathrm{M}$ ferrous ammonium sulphate (Sigma Aldrich). The reaction was initiated by the addition of $75 \mu \mathrm{M} \mathrm{BH}_{4}$ stabilized in $2 \mathrm{mM}$ dithiothreitol (DTT; Fluka Chemie AG, Buchs, Switzerland), carried out for 60 minutes at $25^{\circ} \mathrm{C}$ and stopped by acetic acid followed by 10 minutes incubation at $95^{\circ} \mathrm{C}$. All concentrations mentioned refer to the final concentration in a $100 \mu \mathrm{l}$ reaction mixture. The amount of L-tyrosine production was measured and quantified by HPLC, assayed as triplicates. Three independent experiments were performed.

\subsection{Statistics}

Group mean values were compared by Student's unpaired two-tailed $t$-test. Statistical analyses were performed using GraphPad Prism 4.0c (GraphPad Software, San Diego, USA).

\section{Results}

3.1 Pah $h^{\text {enu1/2 }}$ is a model for compound heterozygous $\mathrm{BH}_{4}$-responsive $\mathrm{PAH}$ deficiency

The heteroallelic $P a h^{\text {enu1/2 }}$ was previously reported as an orthologue for human hyperphenylalaninemia [20] with plasma phenylalanine levels of 147 to $200 \mu \mathrm{M}$ and a 
residual enzyme activity of about $5 \%$ as compared to wild-type mice. We revisited this mouse model in order to reevaluate the biochemical phenotype and PAH enzyme function in vivo and in vitro and to test for responsiveness to $\mathrm{BH}_{4}$. In our experimental setup mean blood phenylalanine concentrations were $54+/-2.1 \mu \mathrm{M}$ for the wild-type, $177+/-25.7 \mu \mathrm{M}$ for $P a h^{\text {enu1/1 }}, 284+/-24.9 \mu \mathrm{M}$ for $P a h^{\text {enu1/2 }}$, and 1115 +/- 54.2 $\mu \mathrm{M}$ for $P a h^{\text {enu2/2 }}$, in ascending order (Fig. 1A). Phenylalanine oxidation, which is a measure of in vivo $\mathrm{PAH}$ enzyme activity, was assessed by a ${ }^{13} \mathrm{C}$-phenylalanine oxidation test $[7,8,16]$. The cumulative recovery of ${ }^{13} \mathrm{CO}_{2}$ (the product of ${ }^{13} \mathrm{C}$ phenylalanine oxidation) after 104 minutes reached $38+/-2.8 \%$ for the wild-type, whereas Pah ${ }^{\text {enu1/1 }}(12+/-1.0 \%)$, Pah $^{\text {enu1/2 }}(9+/-0.8 \%)$, and Pah ${ }^{\text {enu2/2 }}(5+/-0.6 \%)$ showed lower values in descending order (Fig. 1B).

Results obtained from ${ }^{13} \mathrm{C}$-phenylalanine breath tests were substantiated in vitro by overexpression of wild-type, V106A, F263S, and combined overexpression of V106A and F263S PAH, respectively. COS-7 cells transiently transfected with V106A, the in vitro model for $P a h^{\text {enu1/1 }}$, or V106A/F263S, the in vitro model for $P a h^{\text {enu1/2}}$, showed decreased PAH activity in comparison to the wild-type (Fig. 1C). In line with the in vivo experiments, co-transfection of V106A/F263S resulted in a significantly lower enzyme activity than transfection of V106A only. As expected, transfection of F263S resulted in almost no residual enzyme activity. As a next step, we aimed to determine the response of $P a h^{\text {enu1/2 }}$ to pharmacological doses of $\mathrm{BH}_{4}$. A single dose of $\mathrm{BH}_{4}(20 \mu \mathrm{g} / \mathrm{g}$ bw i.p.) significantly reduced blood phenylalanine concentrations of $P a h^{\text {enu1/2 }}$ from $284+/-24.9 \mu \mathrm{M}$ to $135+/-17.2 \mu \mathrm{M}$ and of $P a h^{\text {enu1/1 }}$ from $177+/-25.7 \mu \mathrm{M}$ to $70+/-17.2 \mu \mathrm{M}$, whereas phenylalanine values remained unchanged in wild-type mice and in $P a h^{\text {enu2/2 }}$. Pah ${ }^{\text {enu1/1 }}$ reached blood phenylalanine concentrations close to that of wild-type mice, while $P a h^{\text {enu1/2 }}$ still displayed mild hyperphenylalaninemia after treatment (Fig. 1D). In addition, $\mathrm{BH}_{4}$ 
injection led to an increase in phenylalanine oxidation in $P a h^{\text {enu1/1 }}$ and $P a h^{\text {enu1/2 }}$. The cumulative recovery of ${ }^{13} \mathrm{CO}_{2}$ after 104 minutes attained wild-type level in both $P a h^{e n u 1 / 2}$ and $P a h^{e n u 1 / 1}$. In agreement with the missing effect on blood phenylalanine concentrations, $\mathrm{BH}_{4}$ treatment did not affect phenylalanine oxidation rates in $P a h^{\text {enu2/2 }}$ (Fig. 1E). In wild-type mice, however, $\mathrm{BH}_{4}$ led to a reduction in the cumulative ${ }^{13} \mathrm{CO}_{2}$ recovery, which is in line with the known inhibitory effect of the cofactor on enzyme activity [34].

In COS-7 cells, treatment with $\mathrm{BH}_{4}$ over 24 hours led to an increase in enzyme activity in cells overexpressing wild-type PAH as well as V106A and V106A/F263S (Fig. 1F) with the effect being most pronounced in cells expressing V106A-PAH. Taken together, determination of phenylalanine oxidation mirrored the biochemical phenotype and allowed for sensitive discrimination between all genotypes tested. Moreover, combined analysis of the biochemical and molecular phenotype showed that $P a h^{\text {enu } 1 / 2}$ displays more severe PAH deficiency than $P a h^{\text {enu1/1 }}$ and identified $P a h^{e n u 1 / 2}$ as a compound heterozygous model for human $\mathrm{BH}_{4}$-responsive $\mathrm{PAH}$ deficiency.

\subsection{Pharmacodynamic characterization of $\mathrm{BH}_{4}$ treatment in wild-type and $\mathrm{PAH}$} deficient mice

To characterize the pharmacodynamic effects of $\mathrm{BH}_{4}$ on wild-type and variant $\mathrm{PAH}$ in vivo we selected a combined set of three different endpoints: (i) blood phenylalanine elimination, (ii) blood phenylalanine/tyrosine ratios, and (iii) kinetics of in vivo phenylalanine oxidation.

In wild-type mice a phenylalanine challenge (15 $\mu \mathrm{g} / \mathrm{g}$ bw i.p.) led to no significant changes in blood phenylalanine concentrations (Fig. 2A) or the 
phenylalanine/tyrosine ratio (Fig. 2B). Accordingly, the ${ }^{13} \mathrm{C}$-phenylalanine applied was almost completely oxidized to ${ }^{13} \mathrm{CO}_{2}$ within the first hour (Fig. 2C). In $P a h^{\text {enu1/1 }}$ and $P a h^{\text {enu1/2 }}$ the phenylalanine challenge induced a marked increase in both blood phenylalanine concentrations (Fig. 2A) and blood phenylalanine/tyrosine ratios (Fig. 2B) that did not recover to initial values within 3 hours (Table 1). In agreement with the respective biochemical (blood phenylalanine concentrations) and functional (phenylalanine oxidation) phenotypes, $P a h^{\text {enu1/2 }}$ showed more severe alterations of blood phenylalanine elimination and phenylalanine/tyrosine ratio elevations than $\operatorname{Pah}^{\text {enu1/1 }}$.

The effect of $\mathrm{BH}_{4}$ on phenylalanine elimination and on the phenylalanine/tyrosine ratio was different from that on phenylalanine oxidation, where both $P a h^{\text {enu1/1 }}$ and $P a h^{\text {enu1/2 }}$ reached wild-type levels after treatment (Fig. 1E). Only Pah ${ }^{e n u 1 / 1}$ showed normalization of phenylalanine elimination and the phenylalanine/tyrosine ratio within 120 and 60 minutes, respectively. Both parameters did not significantly decrease in $P_{a h} h^{e n 1 / 2}$ and the blood phenylalanine concentration and the phenylalanine/tyrosine ratio remained elevated 3 hours after $\mathrm{BH}_{4}$ administration (Table 1). In both animal models the rates of phenylalanine oxidation, assessed by determination of delta over baseline, exceeded half maximum values as early as 6.5 minutes post $\mathrm{BH}_{4}$ injection. However, $P a h^{e n u 1 / 1}$ reached maximum oxidation rates at 13 minutes, whereas Pah ${ }^{\text {enu1/2 }}$ displayed a delayed maximum at 26 minutes (Fig. 2C). The resulting elimination constants $\left(\mathrm{K}_{\mathrm{e}}\right)$ for blood phenylalanine again showed lower response to the drug for $\operatorname{Pah}^{\text {enu1/2 }}(0.014)$ than for $P a h^{\text {enu1/1 }}(0.023)$ (Table 1). In summary, the application of the three endpoints presented here allowed for a clear discrimination in pharmacodynamics between the two mouse strains. Differences in the response to the drug were not only confined to the effect size but also observed in terms of effect kinetics. 


\subsection{Pharmacokinetics of $\mathrm{BH}_{4}$}

In order to determine, whether differences in pharmacodynamics were induced by discrepant pharmacokinetic behavior, we quantified total biopterin blood concentrations over time after intraperitoneal injection of $20 \mu \mathrm{g} / \mathrm{g}$ bw of $\mathrm{BH}_{4}$. We observed an increase from $19.4+/-3.1$ to $467.4+/-47.5 \mathrm{nmol} / \mathrm{g} \mathrm{Hb}$ in Pah ${ }^{e n u 1 / 1}$ and from $17.3+/-2.5$ to $558.8+/-68.3 \mathrm{nmol} / \mathrm{g} \mathrm{Hb}$ in $\mathrm{Pah}^{\text {enu1/2}}$. The maximum was reached after 17.5 minutes and concentrations decreased rapidly thereafter. About $70 \%$ of exogenous $\mathrm{BH}_{4}$ was eliminated 60 minutes post application followed by a second slow elimination phase that reached initial values $\left(\operatorname{Pah}^{\text {enu1/1 }} 51.2+/-6.2, \operatorname{Pah}^{\text {enu1/2 }}\right.$ $55.6+/-6.7)$ at 180 minutes. None of the pharmacokinetic parameters $\left(c_{0}, c_{\max }, t_{\max }\right.$, AUC, $\mathrm{t}_{1 / 2}$ ) significantly differed between $P a h^{\text {enu1/1 }}$ and $P a h^{\text {enu1/2 }}$ (Table 2).

\subsection{Effect duration of $\mathrm{BH}_{4}$}

We subsequently aimed to analyze, whether $\mathrm{BH}_{4}$ effect duration diverges between $P a h^{e n u 1 / 1}$ and $P a h^{e n u 1 / 2}$. For this purpose we monitored the time course of ${ }^{13} \mathrm{C}$ phenylalanine oxidation after a single dose of $\mathrm{BH}_{4}$ and analyzed the effect of $\mathrm{BH}_{4}$ on PAH activity in cultured cells over 72 hours.

In both PAH deficient strains phenylalanine oxidation reached its maximum immediately after $\mathrm{BH}_{4}$ application (Fig. $2 \mathrm{C}$ ). In order to compare effect durations we normalized the data defining the highest values as $100 \%$ and the placebo level as 0 $\%$. A single dose of $40 \mu \mathrm{g} / \mathrm{g}$ bw $\mathrm{BH}_{4}$ induced enhanced phenylalanine oxidation for more than 48 hours in $P a h^{\text {enu1/1/1 }}$, while in $P a h^{\text {enu1/2 }}$ phenylalanine oxidation decayed to placebo levels within 18 hours (Fig. 3A). 
These results were confirmed by assessing the long-term effect of $\mathrm{BH}_{4}$ on PAH enzyme activity in COS-7 cells (Fig. 3B). In cells expressing V106A, $\mathrm{BH}_{4}$ treatment normalized enzyme activity, while cells expressing V106A/F263S reached $75 \%$ of wild-type activity. $\mathrm{BH}_{4}$ did not affect enzyme activity in cells transfected with F263S. In addition, we compared the fold increase of enzyme activity over the control (no $\mathrm{BH}_{4}$ treatment) after 24 hours and 72 hours of cell incubation with $\mathrm{BH}_{4}$. At overexpression of V106A the major part of the response occurred within 24 hours (1.54-fold increase) and cultivation for additional 48 hours did not substantially further increase enzyme activity (1.75-fold). By contrast, cells expressing V106A/F263S showed their main increase in enzyme activity (1.9-fold) after prolonged cultivation of 72 hours and not after 24 hours (1.15-fold) (Fig. 3C). In conclusion, $P a h^{\text {enu1/1 }}$ and $P a h^{\text {enu1/2 }}$ showed pronounced differences in effect duration of $\mathrm{BH}_{4}$ treatment. The in vivo effect of $\mathrm{BH}_{4}$ was shorter in $\mathrm{Pah}^{\text {enu1/2 }}$ than in $P a h^{e n u 1 / 1}$. This was demonstrated by showing that the functional effect of the drug on phenylalanine oxidation leveled off more rapidly. In vitro, a prolonged treatment was needed to reach the maximum treatment effect in $P a h^{\text {enu1/2 }}$.

\subsection{Dose effects of $\mathrm{BH}_{4}$}

To further characterize genotype-specific pharmacodynamics we studied the dose response to $\mathrm{BH}_{4}$. Analysis of the cumulative recovery of ${ }^{13} \mathrm{C}$-phenylalanine oxidation at 104 minutes upon single dose $\mathrm{BH}_{4}$ treatment revealed a non-dose-dependent inhibitory effect in the range of 5 to $40 \mu \mathrm{g} / \mathrm{g}$ bw i.p in wild-type mice (Fig. 4A). $P a h^{e n u 1 / 1}$ showed a positive dose response starting at $5 \mu \mathrm{g} / \mathrm{g}$ and reached a plateau at $20 \mu \mathrm{g} / \mathrm{g}$ with no further increase in phenylalanine oxidation at higher doses (Fig. 4B). In the compound heterozygous mouse $P a h^{\text {enu1/2 }}$ we also identified a positive 
dose effect. However, $\mathrm{BH}_{4}$ doses of 30 and $40 \mu \mathrm{g} / \mathrm{g}$ resulted in a lower activity as compared to the peak effect at 10 to $20 \mu \mathrm{g} / \mathrm{g}$ (Fig. 4C). With respect to the effect size $P a h^{\text {enu1/2 }}$ revealed a stronger response as compared to $P a h^{\text {enu1/1 }}$ at 5,10 , and 20 $\mu \mathrm{g} / \mathrm{g}$, respectively (Fig. 4B, C).

In conclusion, $P a h^{e n u 1 / 1}$ and $P a h^{e n u 1 / 2}$ showed a dose dependent and increasing response to $\mathrm{BH}_{4}$ at low doses up to $10 \mu \mathrm{g} / \mathrm{g}$ with no further benefit at higher dosages. Moreover, the results observed for $P a h^{\text {enu1/2 }}$ are in line with a negative dose effect for concentrations above $20 \mu \mathrm{g} / \mathrm{g} \mathrm{BH}_{4}$.

\section{Discussion}

The approval of $\mathrm{BH}_{4}$ marked a paradigm change in the management of phenylketonuria treatment. Clinical studies performed to analyze $\mathrm{BH}_{4}$-responsiveness in patients often focused on the surrogate marker blood phenylalanine concentration as an endpoint. However, this method produced high intraindividual variability and discrepant findings among similar genotypes [23] and therefore proved to be of limited value. Moreover, an animal model with the specific clinical and biochemical phenotype of $\mathrm{BH}_{4}$-responsive $\mathrm{PAH}$ deficiency was not available during the development of the drug. Thus, important insights into pharmacodynamics of $\mathrm{BH}_{4}$ were still lacking, in particular with regard to pharmacogenetics as well as effect size and effect kinetics.

We recently characterized $\mathrm{Pah}^{\text {enu1/1 }}(\mathrm{V} 106 \mathrm{~A} / \mathrm{V} 106 \mathrm{~A})$ as the first animal model for $\mathrm{BH}_{4}$-responsive MHP [16]. This opened up the opportunity for first in vivo investigations in order to elucidate the $\mathrm{BH}_{4}$ mode of action and to substantiate the view of the cofactor being a pharmacological chaperone. The genetic alteration in this mouse does not lead to changes in PAH affinity to the cofactor [16] reflecting the human situation where only few $K_{m}$ variants were found [4, 14, 15, 35-37]. Thus, the 
mode of action of $\mathrm{BH}_{4}$ in $\mathrm{PAH}$ deficiency was not limited to its cofactor action. We showed that pharmacological doses of $\mathrm{BH}_{4}$ attenuate the pathophysiological triad of misfolding, aggregation, and accelerated degradation of the PAH enzyme by conformational stabilization augmenting the effective PAH concentration. This led to the rescue of the biochemical phenotype and enzyme function in vivo. Notably, the pharmaceutical action of the cofactor was confined to the pathological metabolic state of hyperphenylalaninemia [16].

Here we present $P a h^{\text {enu1/2 }}$ (V106A/F263S) as a second mouse model for $\mathrm{BH}_{4}$ responsive PKU. This strain displays compound heterozygosity representing the genotype of the large majority of PKU patients (87\%) [23] that are dealt with in daily clinical routine. Amino acid residues V106 in the regulatory domain and F263 in the catalytic core are conserved between mouse and human but neither V106A nor F263S have so far been identified in human PKU patients. However, the F263L amino acid substitution was described to be also associated with a severe phenotype. A comparison of specific activities of murine and human PAH variants V106A, F263S, and F263L confirmed that amino acid substitutions at the respective loci result in similar effects in both species (Supplementary Table 1). Thus, murine V106A and F263S variants are good models for human $\mathrm{BH}_{4}$-responsive $\mathrm{PAH}$ deficiency.

As previously shown [20] and confirmed in our current study, $P a h^{\text {enu1/2 }}$ exhibits an intermediate phenotype between $P a h^{\text {enu1/1 }}$ and $P a h^{\text {enu2/2. }}$. Hyperphenylalaninemia in vivo is more severe than in $\mathrm{Pah}^{\text {enu1/1 }}$ and less severe than in $\mathrm{Pah} h^{\text {enu2/2 }}$, whereas $\mathrm{PAH}$ activity in vivo and in vitro is lower than in $P a h^{\text {enu1/1 }}$ but higher than in $P a h^{\text {enu2/2. }}$. Analyses of phenylalanine oxidation by ${ }^{13} \mathrm{C}$-phenylalanine breath tests mirrored these differences in severity and were in good agreement with biochemical (blood 
phenylalanine) and molecular (PAH activity) data allowing for high-sensitivity discrimination of genotypes.

We compared pharmacodynamics of $\mathrm{BH}_{4}$ treatment in the two mouse models and observed crucial differences. Heterogeneous results were obtained with respect to the effect size. In the combined phenylalanine $\mathrm{BH}_{4}$-loading test a single load of 20 $\mu \mathrm{g} / \mathrm{g}$ bw $\mathrm{BH}_{4}$ induced a decrease of blood phenylalanine of $67.5 \%$ in $P a h^{\text {enu1/1 }}$ and of only $35.5 \%$ in $\mathrm{Pah}^{\text {enu1/2}}$. This value is in close proximity of the threshold of $30 \%$, an arbitrary but accepted measure for $\mathrm{BH}_{4}$-responsiveness in humans considered to be associated with clinical benefit. By contrast, the effect on in vivo phenylalanine oxidation, the direct measure of PAH activity, was striking in this strain. Treatment with $\mathrm{BH}_{4}$ completely normalized in vivo enzyme activity with the effect being even stronger than in the milder phenotype $P a h^{e n u 1 / 1}$.

Analysis of the effect kinetics further added to dissect the distinct patterns of $\mathrm{BH}_{4}{ }^{-}$ response in the two strains. At the biochemical level, $P a h^{e n u 1 / 2}$ showed slower elimination of pathologically elevated phenylalanine concentrations than $P a h^{\text {enu1/1 }}$. This was mirrored by a less pronounced and delayed reduction of the phenylalanine/tyrosine ratio, an important parameter to judge the extent of metabolic derangement. At the functional level, both strains showed an immediate response to $\mathrm{BH}_{4}$-loading in the breath test, but the peak phenylalanine oxidation upon treatment again was delayed in $P a h^{e n u 1 / 2}$ in comparison to $P a h^{\text {enu1/1/. }}$. Moreover, the duration of the $\mathrm{BH}_{4}$ effect after a single dose was considerably shorter in $P a h^{\text {enu1/2 }}$ than in $P a h^{\text {enu1/1. }}$.

In addition, the two animal models displayed important divergences concerning dose response. Both strains attained maximum in vivo phenylalanine oxidation at a dose of $20 \mu \mathrm{g} / \mathrm{g} \mathrm{bw} \mathrm{BH}$. Yet, $P a h^{\text {enu1/2 }}$ exhibited a response inhibition in the presence of higher dosages, while $P a h^{\text {enu1/1 }}$ reached a plateau. This data is in line with well 
known features of pharmacological chaperones which show inhibitory effects at higher concentrations [38].

Our findings may lead to important conclusions concerning the diagnostic and therapeutic management of patients with PAH deficiency. First, extending the test procedures to assess $\mathrm{BH}_{4}$-responsiveness may allow to draw a more complete picture of the drug response in the single individual. The methods presented in this work can easily and safely be transferred into clinical routine and provide useful endpoints beyond determination of blood phenylalanine concentrations. Second, some patients show a delayed reduction in blood phenylalanine after $\mathrm{BH}_{4}$ loading, these are often referred to as slow responders $[8,22,25,39]$. Our results indicate that this may be rather due to a limited pharmacodynamic effect than to a delayed onset of drug action. Cell culture experiments pointed to a beneficial effect of prolonged treatment for slow responder genotypes and hence suggest appreciation of this fact when testing for and treating $\mathrm{BH}_{4}$-responsive $\mathrm{PAH}$ deficiency. Third, both animal models bear the same mutation responsible for $\mathrm{BH}_{4}$-responsiveness $(\mathrm{V} 106 \mathrm{~A})$, however, the null-mutation on the second allele in the compound heterozygous genotype $P a h^{\text {enu1/2 }}$ had substantial impact on pharmacodynamics. Thus, response to treatment is not exclusively related to the putative milder mutation $[23,24,39]$ and effects induced by interallelic complementation may necessitate careful dose finding procedures in compound heterozygous patients. Fourth, the individual behaviour with regard to effect size, onset of maximum drug action, and effect duration underscores the demand of individual therapeutic regimes for different genotypes. Some patients may for instance benefit from a treatment scheme with several $\mathrm{BH}_{4}$ administrations to translate the effect of the drug on enzyme activity into a sustained effect on biochemical markers. Moreover, in certain patients, higher dosages may diminish the positive treatment effect at a higher risk of possible adverse effects. 
In conclusion, considerable clinical and research effort has been devoted to identifying the conditions for optimal testing for $\mathrm{BH}_{4}$-responsiveness in $\mathrm{PAH}$ deficiency. Our in depth pharmacological analyses of two mouse models with different genotypes are in line with the notion that genotype-driven complexity will require comprehensive evaluation instruments addressing different pharmacodynamic and pharmacokinetic aspects. For this purpose, the diagnostic package including time-dependent blood phenylalanine elimination and phenylalanine/tyrosine ratios as well as kinetics of in vivo phenylalanine oxidation can easily be transferred to and implemented in patients and by this may contribute to individualized diagnostics and treatment of patients suffering from a genetically heterogenous condition.

\section{Acknowledgements}

The authors wish to thank Anja Schultze, Heike Preisler, Maria Trieb, and Bernadette Schmid for excellent technical assistance and Georg Wietzorrek for his support. This work was supported by the Bavarian Genome Research Network (BayGene) and the Dr. Legerlotz-Stiftung Liechtenstein. This article is part of an M.D. thesis to be submitted by A.E. at Ludwig-Maximilians-University, Munich, Germany. 


\section{REFERENCES}

[1] Shiman R, Gray DW, Hill MA. Regulation of rat liver phenylalanine hydroxylase. I. Kinetic properties of the enzyme's iron and enzyme reduction site. J Biol Chem 1994;269:24637-46.

[2] Shiman R, Xia T, Hill MA, Gray DW. Regulation of rat liver phenylalanine hydroxylase. II. Substrate binding and the role of activation in the control of enzymatic activity. J Biol Chem 1994;269:24647-56.

[3] Xia T, Gray DW, Shiman R. Regulation of rat liver phenylalanine hydroxylase. III. Control of catalysis by (6R)-tetrahydrobiopterin and phenylalanine. J Biol Chem 1994;269:24657-65.

[4] Gersting SW, Kemter KF, Staudigl M, Messing DD, Danecka MK, Lagler FB, et al. Loss of function in phenylketonuria is caused by impaired molecular motions and conformational instability. Am J Hum Genet 2008;83:5-17.

[5] Bonafé L, Blau N, Burlina AP, Romstad A, Güttler F, Burlina AB. Treatable neurotransmitter deficiency in mild phenylketonuria. Neurology 2001;57:908-11.

[6] Weglage J, Pietsch M, Feldmann R, Koch HG, Zschocke J, Hoffmann G, et al. Normal clinical outcome in untreated subjects with mild hyperphenylalaninemia. Pediatr Res 2001;49:532-6.

[7] Kure S, Hou DC, Ohura T, Iwamoto H, Suzuki S, Sugiyama N, et al. Tetrahydrobiopterin-responsive phenylalanine hydroxylase deficiency. J Pediatr 1999;135:375-8.

[8] Muntau AC, Röschinger W, Habich M, Demmelmair H, Hoffmann B, Sommerhoff CP, et al. Tetrahydrobiopterin as an alternative treatment for mild phenylketonuria. $\mathrm{N}$ Engl J Med 2002;347:2122-32.

[9] Steinfeld R, Kohlschütter A, Zschocke J, Lindner M, Ullrich K, Lukacs Z. Tetrahydrobiopterin monotherapy for phenylketonuria patients with common mild mutations. Eur J Pediatr 2002;161:403-5.

[10] Trefz FK, Burton BK, Longo N, Casanova MM, Gruskin DJ, Dorenbaum A, et al. Efficacy of sapropterin dihydrochloride in increasing phenylalanine tolerance in children with phenylketonuria: a phase III, randomized, double-blind, placebocontrolled study. J Pediatr 2009;154:700-7.

[11] Burton BK, Grange DK, Milanowski A, Vockley G, Feillet F, Crombez EA, et al. The response of patients with phenylketonuria and elevated serum phenylalanine to treatment with oral sapropterin dihydrochloride (6R-tetrahydrobiopterin): a phase II, multicentre, open-label, screening study. J Inherit Metab Dis 2007;30:700-7.

[12] Levy HL, Milanowski A, Chakrapani A, Cleary M, Lee P, Trefz FK, et al. Efficacy of sapropterin dihydrochloride (tetrahydrobiopterin, 6R-BH4) for reduction of phenylalanine concentration in patients with phenylketonuria: a phase III randomised placebo-controlled study. Lancet 2007;370:504-10.

[13] Lee P, Treacy EP, Crombez E, Wasserstein M, Waber L, Wolff J, et al. Safety and efficacy of 22 weeks of treatment with sapropterin dihydrochloride in patients with phenylketonuria. Am J Med Genet A 2008;146A:2851-9.

[14] Erlandsen H, Pey AL, Gámez A, Pérez B, Desviat LR, Aguado C, et al. Correction of kinetic and stability defects by tetrahydrobiopterin in phenylketonuria patients with certain phenylalanine hydroxylase mutations. Proc Natl Acad Sci U S A 2004;101:16903-8.

[15] Pey AL, Pérez B, Desviat LR, Martínez MA, Aguado C, Erlandsen H, et al. Mechanisms underlying responsiveness to tetrahydrobiopterin in mild phenylketonuria mutations. Hum Mutat 2004;24:388-99.

[16] Gersting SW, Lagler FB, Eichinger A, Kemter KF, Danecka MK, Messing DD, et al. Pahenu1 is a mouse model for tetrahydrobiopterin-responsive phenylalanine hydroxylase deficiency and promotes analysis of the pharmacological chaperone mechanism in vivo. Hum Mol Genet 2010;19:2039-49. 
[17] McDonald JD, Bode VC, Dove WF, Shedlovsky A. The use of N-ethyl-N-nitrosourea to produce mouse models for human phenylketonuria and hyperphenylalaninemia. Prog Clin Biol Res 1990;340C:407-13.

[18] Shedlovsky A, McDonald JD, Symula D, Dove WF. Mouse models of human phenylketonuria. Genetics 1993;134:1205-10.

[19] McDonald JD, Charlton CK. Characterization of mutations at the mouse phenylalanine hydroxylase locus. Genomics 1997;39:402-5.

[20] Sarkissian CN, Boulais DM, McDonald JD, Scriver CR. A heteroallelic mutant mouse model: A new orthologue for human hyperphenylalaninemia. Mol Genet Metab 2000;69:188-94.

[21] Lambruschini N, Pérez-Dueñas B, Vilaseca MA, Mas A, Artuch R, Gassió R, et al. Clinical and nutritional evaluation of phenylketonuric patients on tetrahydrobiopterin monotherapy. Mol Genet Metab 2005;86 Suppl 1:S54-60.

[22] Bélanger-Quintana A, García MJ, Castro M, Desviat LR, Pérez B, Mejía B, et al. Spanish BH4-responsive phenylalanine hydroxylase-deficient patients: evolution of seven patients on long-term treatment with tetrahydrobiopterin. Mol Genet Metab 2005;86 Suppl 1:S61-6.

[23] Zurflüh MR, Zschocke J, Lindner M, Feillet F, Chery C, Burlina A, et al. Molecular genetics of tetrahydrobiopterin-responsive phenylalanine hydroxylase deficiency. Hum Mutat 2008;29:167-75.

[24] Nielsen JB, Nielsen KE, Güttler F. Tetrahydrobiopterin responsiveness after extended loading test of 12 Danish PKU patients with the Y414C mutation. J Inherit Metab Dis 2010;33:9-16.

[25] Fiege B, Bonafé L, Ballhausen D, Baumgartner M, Thöny B, Meili D, et al. Extended tetrahydrobiopterin loading test in the diagnosis of cofactor-responsive phenylketonuria: a pilot study. Mol Genet Metab 2005;86 Suppl 1:S91-5.

[26] Karacić I, Meili D, Sarnavka V, Heintz C, Thöny B, Ramadza DP, et al. Genotypepredicted tetrahydrobiopterin (BH4)-responsiveness and molecular genetics in Croatian patients with phenylalanine hydroxylase (PAH) deficiency. Mol Genet Metab 2009;97:165-71.

[27] Treacy EP, Delente JJ, Elkas G, Carter K, Lambert M, Waters PJ, et al. Analysis of phenylalanine hydroxylase genotypes and hyperphenylalaninemia phenotypes using $\mathrm{L}-[1-13 \mathrm{C}]$ phenylalanine oxidation rates in vivo: a pilot study. Pediatr Res 1997;42:430-5.

[28] Leijssen DP, Elia M. Recovery of $13 \mathrm{CO} 2$ and 14CO2 in human bicarbonate studies: a critical review with original data. Clin Sci (Lond) 1996;91:665-77.

[29] Zurflüh MR, Giovannini M, Fiori L, Fiege B, Gokdemir Y, Baykal T, et al. Screening for tetrahydrobiopterin deficiencies using dried blood spots on filter paper. Mol Genet Metab 2005;86 Suppl 1:S96-103.

[30] Curtius HC, Blau N, Kuster T. Pterins. In: Hommes FA, editor. Techniques in Diagnostic Human Biochemical Genetics. New York: Wiley-Liss, 1991. p. 377-96.

[31] Koch HJ, Uyanik G, Raschka C, Schweizer J. The bi-exponential pharmacokinetic equation is suited to characterize lactate and ammonia concentration versus time data of the ischemic forearm exercise test. Neurol Rehabil 2002;8:235-8.

[32] Martínez A, Knappskog PM, Olafsdottir S, Døskeland AP, Eiken HG, Svebak RM, et al. Expression of recombinant human phenylalanine hydroxylase as fusion protein in Escherichia coli circumvents proteolytic degradation by host cell proteases. Isolation and characterization of the wild-type enzyme. Biochem J 1995;306 ( Pt 2):589-97.

[33] Miranda FF, Kolberg M, Andersson KK, Geraldes CF, Martínez A. The active site residue tyrosine 325 influences iron binding and coupling efficiency in human phenylalanine hydroxylase. J Inorg Biochem 2005;99:1320-8.

[34] Phillips RS, Kaufman S. Ligand effects on the phosphorylation state of hepatic phenylalanine hydroxylase. J Biol Chem 1984;259:2474-9.

[35] Knappskog PM, Flatmark T, Aarden JM, Haavik J, Martínez A. Structure/function relationships in human phenylalanine hydroxylase. Effect of terminal deletions on the 
oligomerization, activation and cooperativity of substrate binding to the enzyme. Eur $\mathrm{J}$ Biochem 1996;242:813-21.

[36] Leandro P, Rivera I, Lechner MC, de Almeida IT, Konecki D. The V388M mutation results in a kinetic variant form of phenylalanine hydroxylase. Mol Genet Metab 2000;69:204-12.

[37] Sanford M, Keating GM. Sapropterin: a review of its use in the treatment of primary hyperphenylalaninaemia. Drugs 2009;69:461-76.

[38] Fan JQ. A counterintuitive approach to treat enzyme deficiencies: use of enzyme inhibitors for restoring mutant enzyme activity. Biol Chem 2008;389:1-11.

[39] Zurflüh MR, Fiori L, Fiege B, Ozen I, Demirkol M, Gärtner KH, et al. Pharmacokinetics of orally administered tetrahydrobiopterin in patients with phenylalanine hydroxylase deficiency. J Inherit Metab Dis 2006;29:725-31. 
Table 1. Phenylalanine kinetics and phenylalanine/tyrosine ratios

\begin{tabular}{|c|c|c|c|c|c|c|c|c|}
\hline & $\mathrm{BH}_{4}$ & $\mathrm{Phe}_{0}[\mu \mathrm{mol} / \mathrm{l}]$ & $\mathrm{Phe}_{180}[\mu \mathrm{mol} / \mathrm{l}]$ & $P$ value & $\mathrm{K}_{\mathrm{e}}$ & Phe/Tyr 0 & Phe/Tyr ${ }_{180}$ & $P$ value \\
\hline \multirow{2}{*}{$P a h^{e n u 1 / 1}$} & - & $109.10 \pm 5.4$ & $153.33 \pm 19.3$ & \multirow{2}{*}{0.0097} & - & $2.62 \pm 0.1$ & $4.79 \pm 0.4$ & \multirow{2}{*}{0.0035} \\
\hline & + & $120.74 \pm 16.5$ & $61.64 \pm 3.9$ & & 0.023 & $3.65 \pm 0.3$ & $1.73 \pm 0.1$ & \\
\hline \multirow{2}{*}{$P a h^{e n u 1 / 2}$} & - & $187.29 \pm 19.8$ & $209.50 \pm 35.1$ & \multirow{2}{*}{ n.s. } & - & $4.71 \pm 0.6$ & $5.65 \pm 1.0$ & \multirow{2}{*}{ n.s. } \\
\hline & + & $174.94 \pm 20.6$ & $136.9 \pm 17.3$ & & 0.014 & $5.38 \pm 0.8$ & $3.65 \pm 0.9$ & \\
\hline BTBR & - & $53.70 \pm 1.8$ & $56.61 \pm 5.0$ & - & 0.015 & $2.15 \pm 0.2$ & $2.49 \pm 0.2$ & \\
\hline
\end{tabular}

Phenylalanine kinetics and phenylalanine/tyrosine ratios were determined after a phenylalanine load of $15 \mu \mathrm{g} / \mathrm{g}$ bw i.p. with and without simultaneous $\mathrm{BH}_{4}$ load (20 $\mu \mathrm{g} / \mathrm{g}$ bw i.p.) to wild-type (BTBR), $P a h^{\text {enu1/1 }}$ and $P a h^{\text {enu1/2 }}$. Phenylalanine concentrations and phenylalanine/tyrosine ratios are given as means \pm s.e.m. The elimination constant $\left(\mathrm{K}_{\mathrm{e}}\right)$ was determined using a one-phase exponential function. Unpaired two-tailed students $t$-tests were applied to test the difference between untreated and treated animals (n.s., not significant). 
Table 2. Determination of pharmacokinetic parameters.

\begin{tabular}{llll}
\hline & $P a h^{\text {enu1/1 }}$ & $P a h^{\text {enu1/2 }}$ & $P$ value \\
\hline $\mathrm{C}_{0}(\mathrm{nmol} / \mathrm{g} \mathrm{Hb})$ & $19.4 \pm 3.1$ & $17.3 \pm 2.5$ & 0.5 \\
$\mathrm{C}_{\max }(\mathrm{nmol} / \mathrm{g} \mathrm{Hb})$ & $467.6 \pm 47.5$ & $558.8 \pm 68.3$ & 0.3 \\
$\mathrm{t}_{\max }(\mathrm{min})$ & $17.5 \pm 2.5$ & $17.5 \pm 2.5$ & 1 \\
$\mathrm{AUC}_{180 \min }$ & $23769 \pm 2341$ & $24522 \pm 2638$ & 0.8 \\
$\mathrm{t}_{1 / 2}(\mathrm{~min})$ & $26.3 \pm 2.8$ & $26.3 \pm 2.7$ & 0.98 \\
\hline
\end{tabular}

The following pharmacokinetic parameters were determined in $P a h^{e n u 1 / 1}$ and Pah ${ }^{\text {enu1/2: }} c_{0}$ initial concentration, $c_{\max }$ peak concentration, $t_{\max }$ time to peak concentration, AUC area under the concentration vs. time curve at 0 to 180 minutes, $t_{1 / 2}$ elimination half-life. 
Figure captions

Fig. 1. Characterization of the biochemical and molecular phenotype of wild-type and $\mathrm{PAH}$ deficient mice and evaluation of $\mathrm{BH}_{4}$-responsiveness.

(A) Basal levels of blood phenylalanine in the wild-type (WT), Pah ${ }^{\text {enu1/1 }}\left(\mathrm{enu}^{1 / 1}\right)$, $\mathrm{Pah}^{\mathrm{enu} 1 / 2}\left(\mathrm{enu}^{1 / 2}\right)$, and $\mathrm{Pah}^{\text {enu2/2 }}\left(\mathrm{enu}^{2 / 2}\right)$. (B) ${ }^{13} \mathrm{C}$-phenylalanine oxidation in vivo assessed in wild-type, $P a h^{\text {enu1/1 }}, P a h^{\text {enu1/2 }}$, and $P a h^{\text {enu2/2 }}$ expressed as cumulative ${ }^{13} \mathrm{CO}_{2}$ recovery at 104 minutes after application of ${ }^{13} \mathrm{C}$-phenylalanine $(15 \mu \mathrm{g} / \mathrm{g}$ bw i.p.). (C) In vitro PAH activity in COS-7 cells transiently expressing murine wild-type and variant $\mathrm{PAH}$. Values were normalized to wild-type activity without $\mathrm{BH}_{4}$ treatment. (D) Blood phenylalanine before (open circles) and 120 minutes after a single dose of $20 \mu \mathrm{g} / \mathrm{g}$ bw i.p. $\mathrm{BH}_{4}$ (closed circles). (E) ${ }^{13} \mathrm{C}$-phenylalanine oxidation in vivo assessed

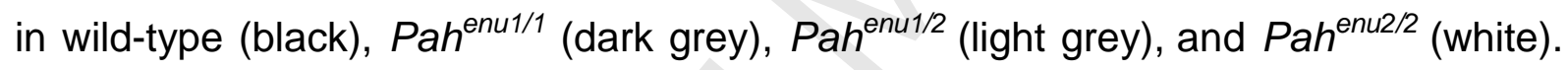
Data points represent cumulative ${ }^{13} \mathrm{CO}_{2}$ recovery after application of ${ }^{13} \mathrm{C}$ phenylalanine (15 $\mu \mathrm{g} / \mathrm{g}$ bw i.p.) and a simultaneous injection of placebo (sodium chloride $0.9 \%$, ascorbic acid $1 \%)$ or $\mathrm{BH}_{4}(20 \mu \mathrm{g} / \mathrm{g}$ bw i.p.). Samples were collected in 6.5 minute intervals over a 104 minute period. (F) In vitro PAH activity in COS-7 cells transiently expressing murine wild-type and variant PAH upon 24 hours incubation with $\mathrm{BH}_{4}\left(43 \mu \mathrm{M}\right.$, grey bars) and without $\mathrm{BH}_{4}$ supplementation (black bars). Values were normalized to wild-type activity without $\mathrm{BH}_{4}$ supplementation. All data are given as means \pm s.e.m. and the significance is indicated $\left({ }^{*} P<0.05\right.$, ${ }^{* *} P<0.01$, ${ }^{* \star *}$ $P<0.001)$.

Fig. 2. Characterization of $\mathrm{BH}_{4}$ effects on $\mathrm{PAH}$ function in vivo.

(A) Blood phenylalanine elimination and (B) blood phenylalanine/tyrosine ratio (Phe/Tyr ratio) were assessed in $P a h^{\text {enu1/1 }}$ and $P a h^{\text {enu1/2 }}$ mice in comparison to 
untreated wild-type mice. The effect of simultaneous challenge of unlabelled phenylalanine $(15 \mu \mathrm{g} / \mathrm{g} \mathrm{bw})$ and $\mathrm{BH}_{4}(20 \mu \mathrm{g} / \mathrm{g} \mathrm{bw})$ versus placebo (sodium chloride $0.9 \%$, ascorbic acid $1 \%$ ) was measured over a 180 minute period and data points representing the decrease in blood phenylalanine concentrations were fitted using a one-phase exponential function. The inset represents blood phenylalanine elimination in wild-type mice at a different scale. (C) Fractional ${ }^{13} \mathrm{CO}_{2}$ recovery in ${ }^{13} \mathrm{C}$ phenylalanine oxidation tests (delta over baseline, DOB) of wild-type mice (WT), $P a h^{e n u 1 / 1}$ and $P a h^{e n u 1 / 2}$. The measurement was performed in 6.5 minute intervals over a 104 minute period after simultaneous injection of $\mathrm{BH}_{4}(20 \mu \mathrm{g} / \mathrm{g}$ bw $)$ and phenylalanine (15 $\mu \mathrm{g} / \mathrm{g} \mathrm{bw}$ ) (closed circles) or placebo (open circles). To depict the immediate onset of the $\mathrm{BH}_{4}$ effects, the differences of fractional recovery ( $\mathrm{DOB}_{\mathrm{BH} 4^{-}}$ $\mathrm{DOB}_{\text {placebo) }}$ within the first four time points are given in the insets. All data are given as means \pm s.e.m.

Fig. 3. In vivo and in vitro characterization of $\mathrm{BH}_{4}$ effect duration.

(A) Effect duration of $\mathrm{BH}_{4}$ in $P a h^{\text {enu1/1 }}$ and $P a h^{\text {enu1/2 }}$ mice expressed as relative recovery of ${ }^{13} \mathrm{CO}_{2}$ at 104 minutes. $\mathrm{BH}_{4}$ was administered $90,24,18,9,6,4.5$ or 3 hours before or simultaneously to ${ }^{13} \mathrm{C}$-phenylalanine and recovery of ${ }^{13} \mathrm{CO}_{2}$ was measured subsequently. Data were normalized defining the maximum recovery as $100 \%$ and the placebo level as $0 \%$. Lines depict the difference in phenylalanine oxidation and are merely to guide the eye. (B) In vitro PAH activity in COS-7 cells transiently expressing murine wild-type and variant PAH upon 72 hours incubation with $\mathrm{BH}_{4}\left(43 \mu \mathrm{M}\right.$, grey bars) and without $\mathrm{BH}_{4}$ supplementation (black bars). Values were normalized to wild-type activity without $\mathrm{BH}_{4}$ supplementation. (C) Comparison of in vitro PAH enzyme activities. Fold increase describes the ratio between enzyme 
activities determined with and without addition of $\mathrm{BH}_{4}(43 \mu \mathrm{M})$ after 24 hours (black bars) and 72 hours (grey bars) incubation. All data are given as means \pm s.e.m.

Fig. 4. Dose effect of $\mathrm{BH}_{4}$ in vivo.

Effect of $\mathrm{BH}_{4}$ on phenylalanine oxidation expressed as cumulative recovery at 104 minutes measured in wild-type (WT) (A), $P_{a h}^{e n u 1 / 1}(B)$, and $P a h^{e n u 1 / 2}(C)$. Data are given as means \pm s.e.m. and the significance is indicated $\left({ }^{*} P<0.05,{ }^{* *} P<0.01\right.$, *** $P<0.001)$ 
Figure 1
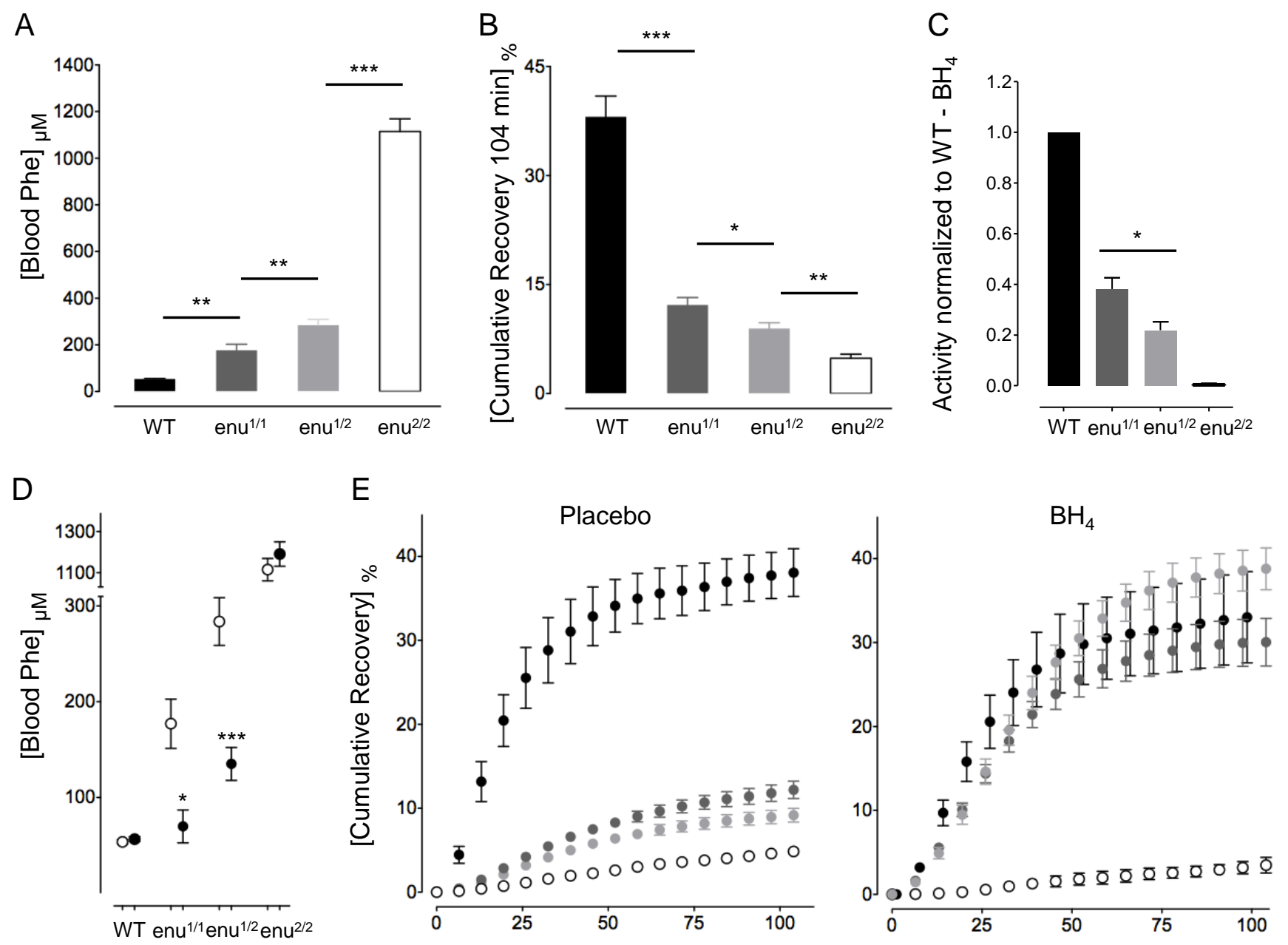

$[\mathrm{t}]_{\min }$

(

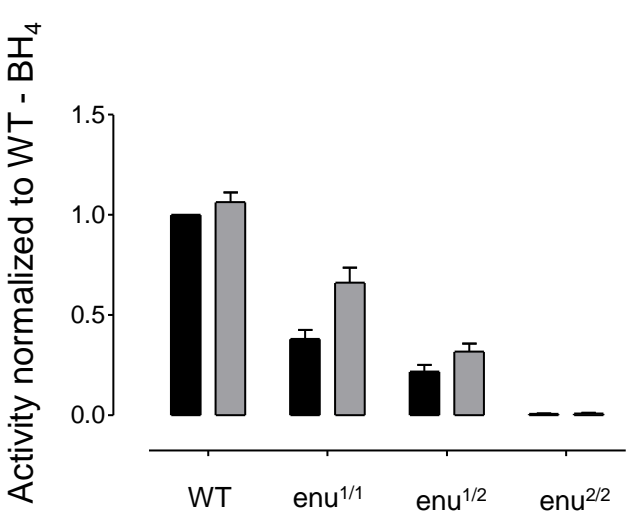


Figure 2

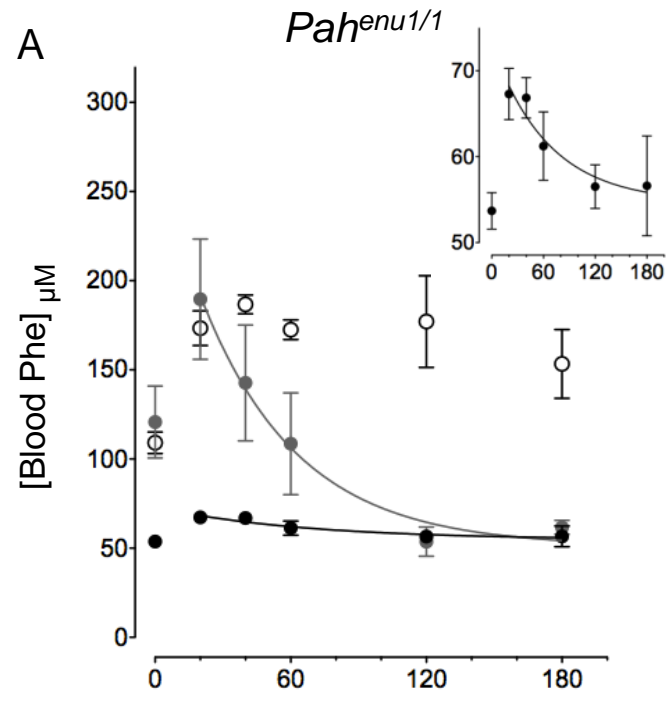

[t] min

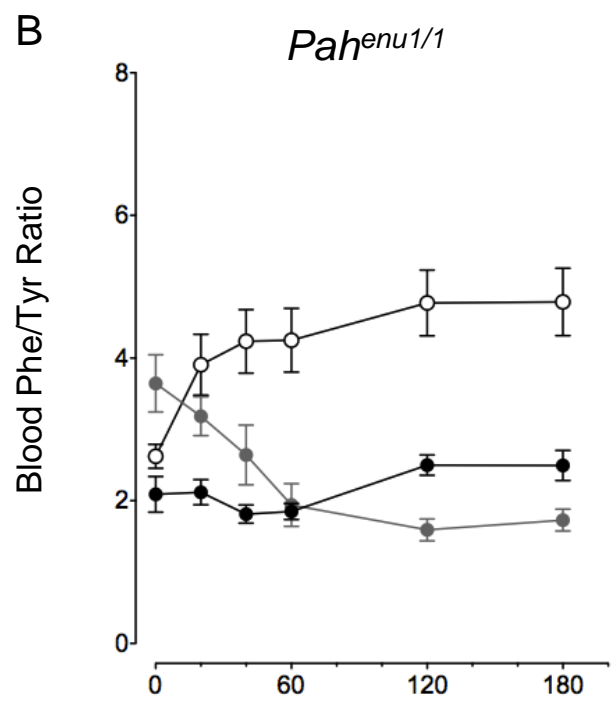

[ t ] min
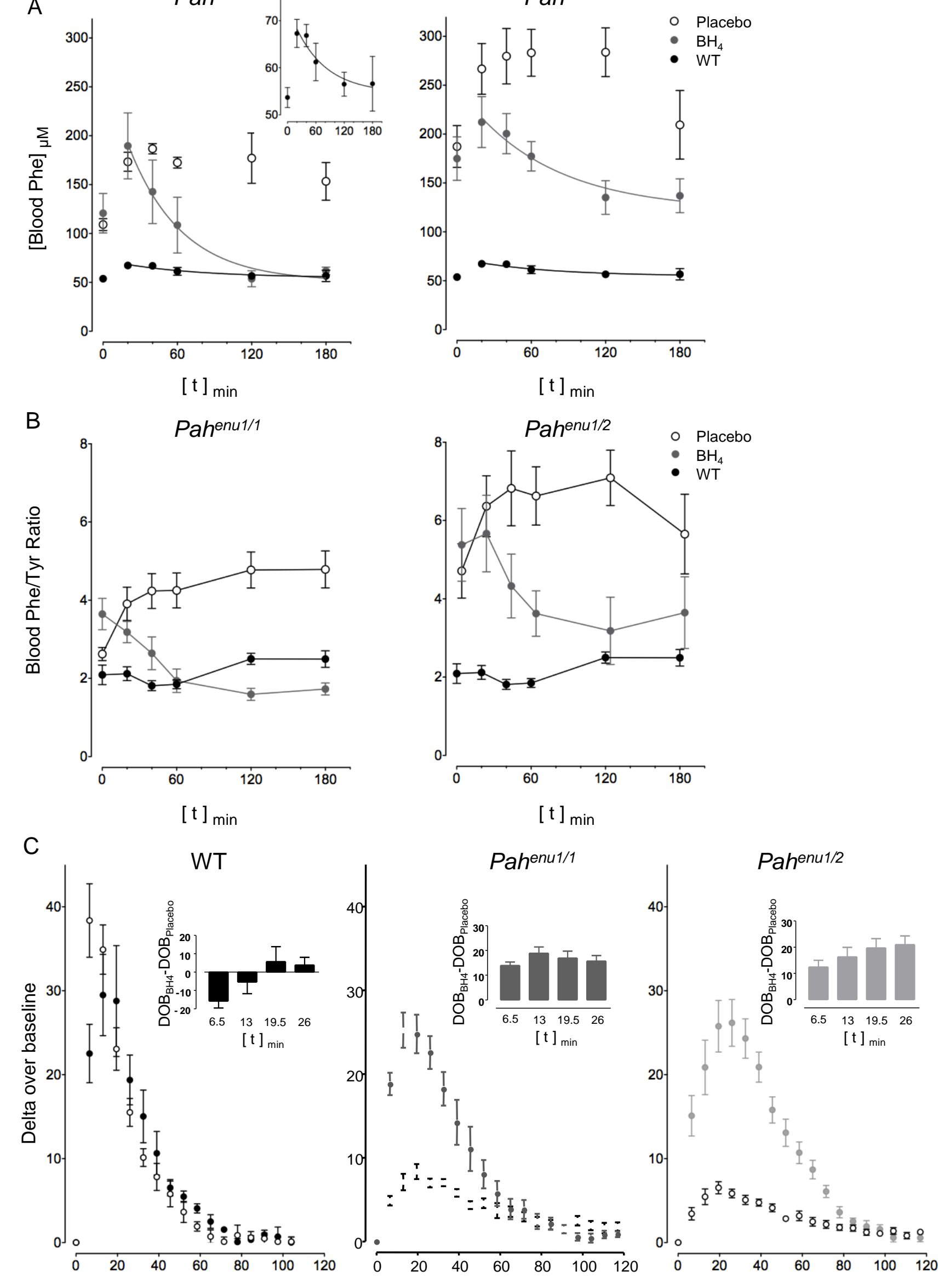

[t] min

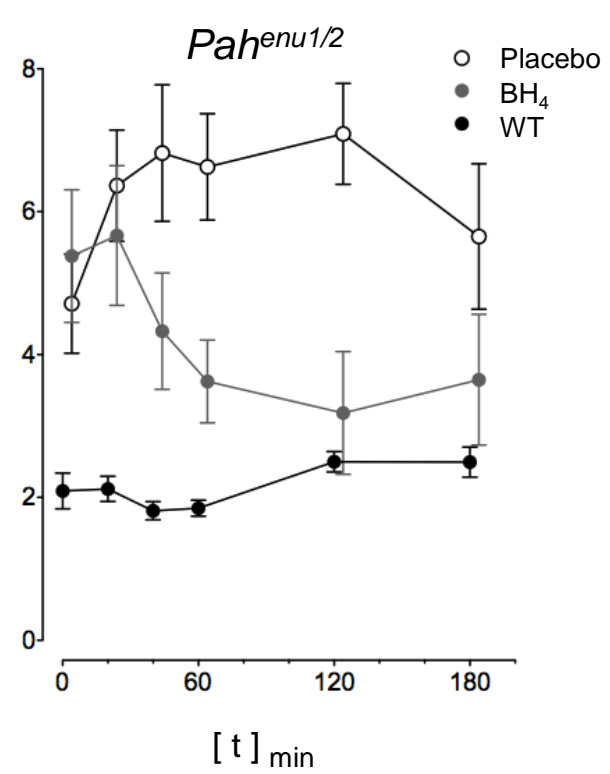


Figure 3

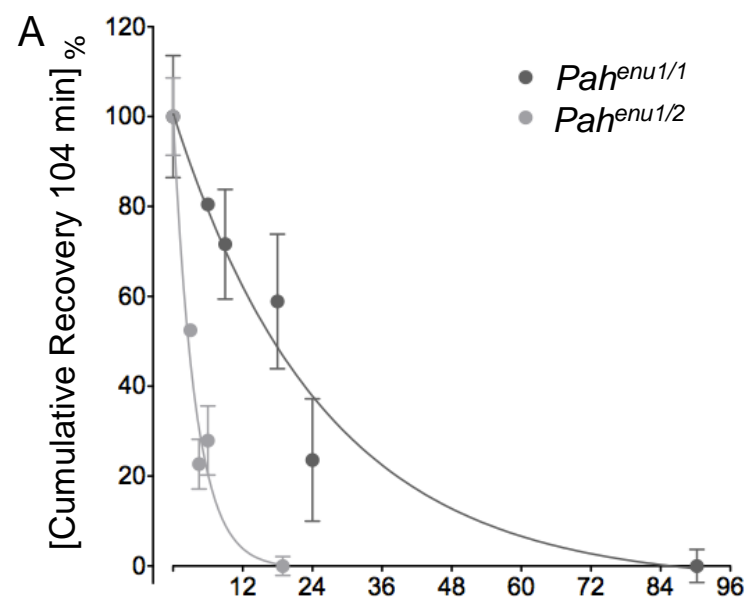

B

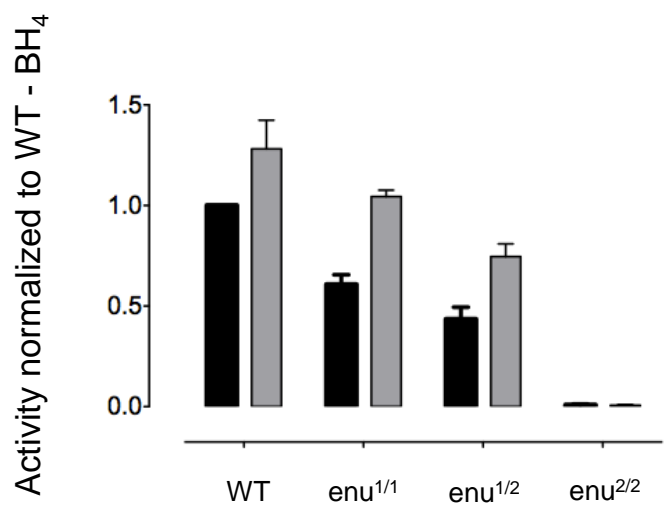

C

[t] $\mathrm{h}$

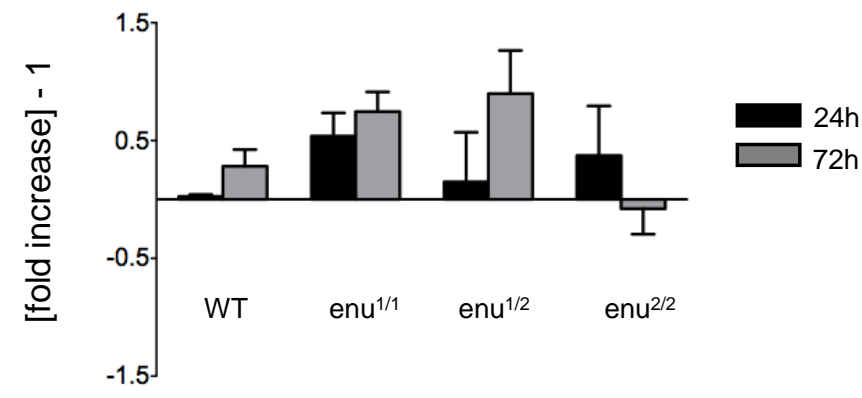


Figure 4

A

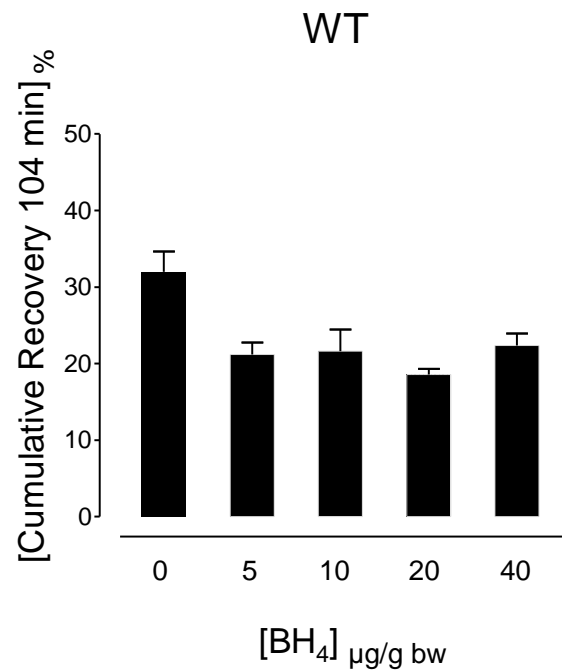

B

Pahenu1/1

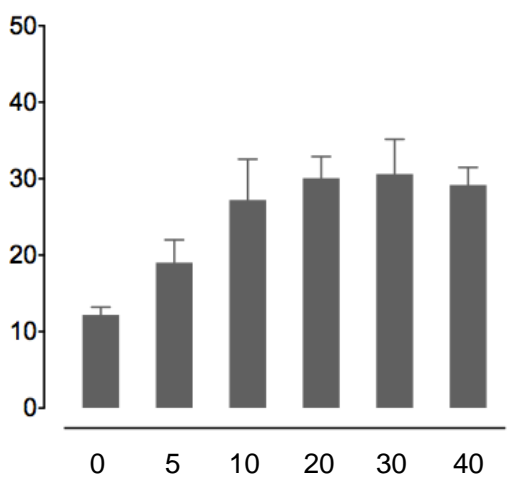

$\left[\mathrm{BH}_{4}\right]_{\mu \mathrm{g} / \mathrm{g} \text { bw }}$
C

Pahenu1/2

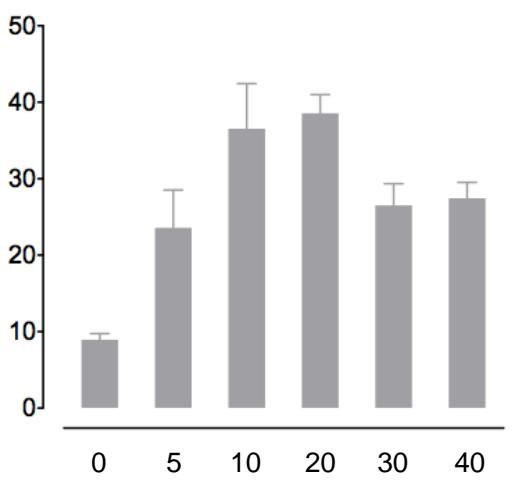

$\left[\mathrm{BH}_{4}\right]_{\mu \mathrm{g} / \mathrm{g} \text { bw }}$ 
Table S1. Steady state enzyme kinetic parameters of wild-type and variant murine PAH proteins

\begin{tabular}{lc}
\hline Genotype & $\begin{array}{c}\text { Specific activity } \\
\text { (nmol Tyr/min x mg protein) }\end{array}$ \\
\hline WT hsPAH & $3115 \pm 149$ \\
WT MmPAH & $2628 \pm 293$ \\
V106A HsPAH & $2947 \pm 260$ \\
V106A MmPAH & $3125 \pm 101$ \\
F263S HsPAH & $235 \pm 51$ \\
F263L HsPAH & $159 \pm 51$ \\
F263S MmPAH & $166 \pm 16$ \\
\hline
\end{tabular}

Recombinant tetrameric human (HsPAH) and murine (MmPAH) PAH were expressed as MBP-PAH fusion proteins in $E$. coli. Specific activity was determined at standard L-phenylalanine $(1 \mathrm{mM})$ and $\mathrm{BH}_{4}(75 \mu \mathrm{M})$ concentrations with L-phenylalanine preincubation Values are given as means \pm SEM of $n=3$ experiments. 
$P a h^{e n u 1 / 2}$ is a mouse model for compound heterozygous phenylalanine hydroxylase deficiency and the pharmacological chaperone $6 R$-L-erythro-5,6,7,8-tetrahydrobiopterin rescues in vivo enzyme activity in $P a h^{e n u 1 / 1}$ and in Pah ${ }^{e n u 1 / 2}$ but shows genotype-specific pharmacodynamics.

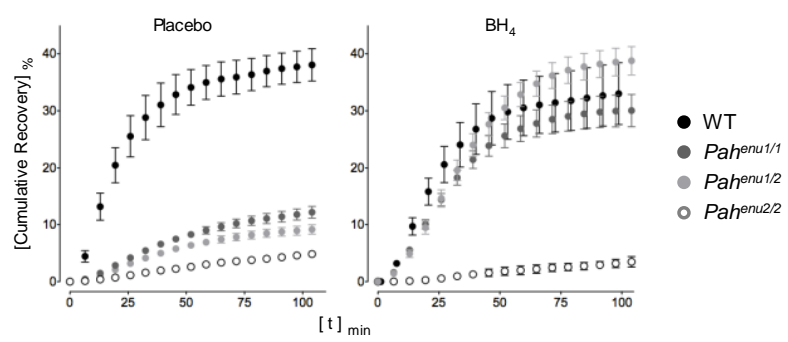

